\title{
Live Weight Estimation of Gwembe Goat (Capra hircus) from Measurement of Thoracic Girth
}

\author{
Parés, P-M. ${ }^{1}$; Mwaanga, E.S. ${ }^{2}$; Caballero, M. ${ }^{1}$; Sabaté, J. \\ Valenzuela, $\mathbf{S}^{1}$
}

1 Dept. of Animal Production, University of Lleida. Av. Alcalde Rovira Roure, 191. E25198 Lleida (Catalunya, Spain) peremiquelp@prodan.udl.cat

2 Dept. of Biomedical Sciences. University of Zambia

With 2 figures \& 1 table $\quad$ Received December 2011, accepted for publication January 2012

\section{Abstract}

Thoracic girth was taken and correlated with live weight from 41 goats (30 females and 11 males) in South Zambia under on farm condition. Live weight was estimated using a linear model. Coefficient of determination $\left(R^{2}\right)$ values was 0.71 . The predictive equation for the live weight from thoracic girth $\mathrm{LV}(\mathrm{kg})=$ $(0.659 \times \mathrm{TG})(\mathrm{cm})-17.467$ can be considered enough satisfactory.

\section{Keywords}

Barometry, buck, body measurments.

\section{Introduction}

Body measurements can be used to predict live weight fairly well in the situation where weighbridges are not available (Berge, 1977; Buvanendran et al., 1980; Gooner- wardene and Sahaayuraban, 1983). The accuracy of functions used to predict live weight or growth characteristics from live animal measurements is of immense financial contribution to livestock production enterprises. The ability of the producer and buyers of livestock to relate live animal measurements to an easily obtainable measure is essential for a better production and value-based trading systems. This ability will also adequately reward livestock stockmen rather than the middlemen that tend to gain more profit in livestock production business, especially in the developing countries.

The objective of the present study was to estimate live weight based on a linear body measurement on Gwembe goat (Capra hircus) from Zambia. Being a meat purpose breed, with high hardiness, it seemed interesting to provide stockmen to an easy tool to esti- 
mate the live weight of their animals.

\section{Material and Methods}

\section{Animals}

The data for this study were obtained from 41 goats (30 females and 11 males) from different flocks kept extensively in different farms of the Lusitu area, Gwembe Valley, at South of Zambia. Animals were kept under traditional management: no routine health management system is applied and the goats are routinely bred following heat apparition to rams under non controlled natural mating, and no supplementary feed is provided. Only those animals considered pure breed and of apparent good health were considered for this study. Field data collection was performed during August 2011 (dry season).

\section{Live animal measurement}

Animals were weighed suspended on a hanging dynamometer. Thoracic girth was measured as the body circumference immediately caudal to the front leg and was measured with a flexible tape. Measurements were performed by different people.

\section{Statistical analysis}

The PAST software (Hammer et al., 2001) was used to obtain the statis- tics of the two variables and to test a linear regression to obtain prediction equations of live weight.

\section{Results and Discussion}

The results obtained for the studied animals (Table 1) showed that mean weight ranged between 13.1$32.7 \pm 5.4 \mathrm{~kg}$ and $12.0-27.1 \pm 4.8 \mathrm{~kg}$ for females and males respectively (Figure 1). Varying range of scatter observed in the weight distribution (CV between 24.7 and $26.2 \%$ ) can be attributed to the fact that the animals are all raised under slightly different management or environmental conditions. Both measurements presented a normal distribution. No statistical differences appeared between sexes for thoracic girth. Pearson (raw) correlation between live weight and thoracic girth was 0.84335 . The lineal regression and the predictive equation for body weight are presented in Figure (2). Coefficient of determination $\left(R^{2}\right)$ value was 0.71 . From the obtained field data the formula LV $(\mathrm{kg})=$ [0.659 x TG] $(\mathrm{cm})-17.467$ could be established as a good predictor.

Lungu (in Lovelace et al., 1993) established another formula for Zambian goats $(\mathrm{LV}=[0.89 \times \mathrm{TG}]-$ 33.78 , but it seems less accurate than the obtained in thus study $(9.7$ $\%$ of difference in our research, 210 
in theirs). In this study, our animals were lighter than the studied by Lungu (average live weight $=31 \mathrm{~kg}$ for Gwembe females).

\section{Conclusion}

This report has demonstrated that a prediction equation for live weight using the thoracic girth is possible and that this measurement can predict body weight with good precision. This observation agrees with many previous publications for donkeys (de Aluja et al., 2005), goat (Olatunji \& Adeyemo, 2009), sheep (Afolayan et al., 2006; Parés, 2008), etc. The thoracic girth measurement is easily performed, being the distance around the body of the animal immediately behind the front legs. Probably a multiple regression with the addition of other measurements to chest girth would result in significant improvements in accuracy of prediction. However, under field conditions, live weight estimation using chest girth alone would be preferable because of difficulty of the proper animal restraint during measurement. This thus reduces the practical usefulness of using other body measurements in conjunction with chest girth.

But it would be ridiculous to say that this would mean that the animals with thicker thorax would tend to be more profitable in terms of reproduction. Selection according uniquely to thoracic girth is extremely risky and also dangerous. It must be an obvious truth that a male which gets valuable daughters is worth more as a breeder than another who has thicker thorax but gets mediocre and bad daughters. Stockmen must be convinced that the way a buck or she-goat breeds is the only really efficient way to test his worth, so the live weight is basically a tool to evaluate animals for meat purposes.

\section{Acknowledgements}

The authors acknowledge the local stockmen for animal management and data collection. The assistance of Lusitu technicians is also appreciated, as well the useful help provided by the veterinarias Andrew Kataba and Sulani Kayz. We wish also to acknowledge the "Oficina de Cooperació i Solidaritat" of the University of Lleida for funding a livestock research in Zambia (2011).

\section{References}

Afolayan, R.A., Adeyinka,I.A.

Lakpini, C.A.M. (2006): The estimation of live weight from body measurements in Yankasa sheep. Czech J. Anim. Sci., 51 (8): 343-348.

Berge S. (1977): On the estimation 
of weight and increase in weight by means of the chest girth in Norwegian red cattle at the Agricultural University at As, Norway in the years 1972 and 1974. Acta Agric. Scand. 27: 65-66.

Buvanendran V., Umoh J.E., Abu bakar B.Y. (1980): An evaluation of body size as related to weight of three West African breeds of cattle in Nigeria. J.Agric.Sci. 95: 219-224. de Aluja AS, Tapia Pérez G, López $F$, Pearson RA. (2005): Live weight estimation of donkeys in central Mexico from measurement of thoracic circumference. Trop. Anim. Health Prod. Nov; 37 Suppl 1: 159-71.

Goonerwardene L.A., Sahaayuruban P. (1983): Analysis of body measurements and prediction of live weight in crossbred Lanka bulls. In: Proc. 5th World Conf. Prod., 2: 27-28.

Hammer, $\varnothing$. , Harper, D.A.T., and Ryan,P.D. (2001): PAST: Paleontological Statistics
Software Package for Education and Data Analysis. Palaeontologia Electronica 4(1).http://palaeoelectronica. org/2001 1/past/issue1 01.h tm.

Lovelace, C.E.A., Lungu, J.C.N., Masebe ,P.O.C.S., Sakala, B., Nyivenda, I., Sikazwe, G., Mizinga, K.M. (1993): Reproductive performance of Zambian goats under drought conditions. In: Improving the productivity of indigenous African Livestock. Internat. Atomic Energy Agency: 73-80. Austria.

Olatunji-Akioye, A.O., Adeyemo, O.K. (2009): Liveweight and Chest Girth Correlation in Commercial Sheep and Goat Herds in Southwestern Nigeria. Int. J. Morphol. 27(1):49-52.

Parés,S P.M. (2008): Caracterització estructural i racial de la raça ovina Aranesa. Ph. T. Universitat Autònoma de Barcelona, Barcelona 
Weight estimation of Gwembe goat

Pares et al.

Table (1): Summary of live-measurement traits for GOATS ( $N=30$ females and 11 males).

LW: Live weight $(\mathrm{kg})$; TG: thoracic girth (cm).

\begin{tabular}{lcc|ccc}
\hline FEMALES & LV & TG & MALES & LV & TG \\
\hline Min. & 13.1 & 46.0 & & 12.0 & 45.5 \\
Max. & 32.7 & 83.5 & & 27.1 & 72.0 \\
Mean & 22.0 & 60.0 & & 18.3 & 53.83 \\
Stand. Dev. & 5.429 & 7.761 & & 4.802 & 8.310 \\
Median & 20.4 & 59.8 & & 17.2 & 52.0 \\
Skewness & 0.245 & 0.739 & & 0.569 & 1.046 \\
Kurtosis & -1.180 & 1.473 & & -0.747 & 0.730 \\
CV (\%) & 24.68 & 12.94 & & 26.18 & 15.43 \\
Shapiro-Wilk W & 0.936 & 0.957 & & 0.934 & 0.884 \\
P (normal) & 0.072 & 0.265 & & 0.453 & 0.118 \\
\hline
\end{tabular}

Females:

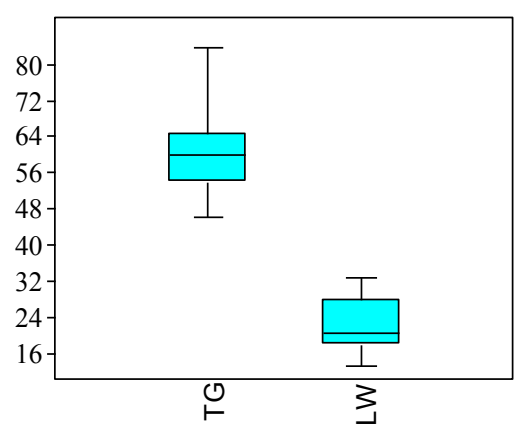

Males:

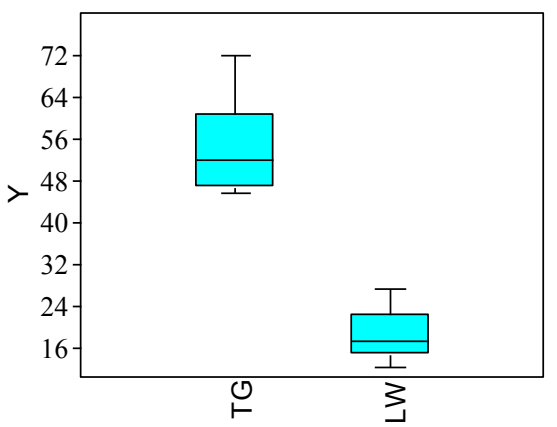

Fig (1): Box plot (average \pm standard deviation) for live weight (LW) and thoracic girth (TG) form females and for males. 


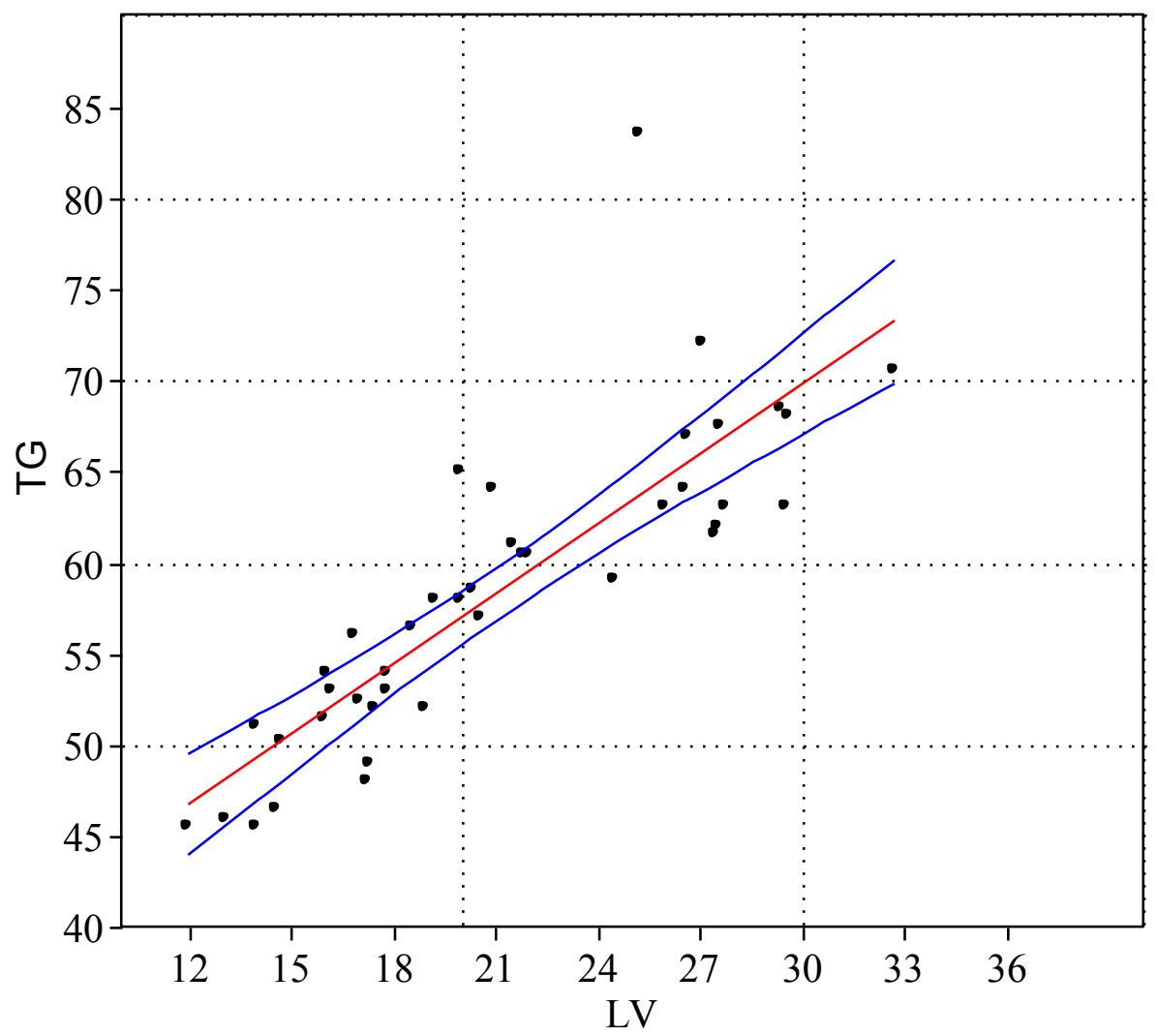

Fig (2): Linear fit for live weight (LW) and thoracic girth (TG) and RMA analysis. (95 \% confidence)

$\operatorname{LV}(\mathrm{kg})=(0.659 \times \mathrm{TG})(\mathrm{cm})-17.467$

RMA Regression

Slope a: $\quad 0.65974$

Intercept b: $\quad-17.467$

Std. err. a: $\quad 0.056768$

Std. err. b: $\quad 11.189$

Chi squared: 0

r: $\quad 0.84335$

$\mathrm{R}^{2}: \quad 0.71125$

t statistic: $\quad 9.8012$

p(uncorrel): $\quad 4.505 \mathrm{E}-12$

Permutat. p: 0.0001

$p(a=1): 5.282 E-07$

$95 \%$ bootstrapped confidence intervals:

a: $[0.5001 ; 0.8068]$

b: [-25.38; -8.735] 